\title{
Radiological and functional lung sequelae of COVID-19: a systematic review and meta-analysis
}

\author{
Matsuo So ${ }^{1}$, Hiroki Kabata ${ }^{2}$, Koichi Fukunaga ${ }^{2}$, Hisato Takagi ${ }^{3}$ and Toshiki Kuno ${ }^{1 *}$
}

\begin{abstract}
Background: The coronavirus disease 2019 (COVID-19) causes a wide spectrum of lung manifestations ranging from mild asymptomatic disease to severe respiratory failure. We aimed to clarify the characteristics of radiological and functional lung sequelae of COVID-19 patients described in follow-up period.

Method: PubMed and EMBASE were searched on January 20th, 2021 to investigate characteristics of lung sequelae in COVID-19 patients. Chest computed tomography (CT) and pulmonary function test (PFT) data were collected and analyzed using one-group meta-analysis.

Results: Our search identified 15 eligible studies with follow-up period in a range of 1-6 months. A total of 3066 discharged patients were included in these studies. Among them, 1232 and 1359 patients were evaluated by chest CT and PFT, respectively. The approximate follow-up timing on average was 90 days after either symptom onset or hospital discharge. The frequency of residual CT abnormalities after hospital discharge was $55.7 \%$ (95\% confidential interval $\left.(C I) 41.2-70.1, P^{2}=96.2 \%\right)$. The most frequent chest CT abnormality was ground glass opacity in $44.1 \%(95 \%$ Cl 30.5-57.8, $\left.P^{2}=96.2 \%\right)$, followed by parenchymal band or fibrous stripe in $33.9 \%$ (95\% Cl 18.4-49.4, $\left.P^{2}=95.0 \%\right)$. The frequency of abnormal pulmonary function test was $44.3 \%\left(95 \% \mathrm{Cl} 32.2-56.4, I^{2}=82.1 \%\right)$, and impaired diffusion capacity was the most frequently observed finding in $34.8 \%$ (95\% Cl 25.8-43.8, $\left.P^{2}=91.5 \%\right)$. Restrictive and obstructive patterns were observed in $16.4 \%$ (95\% Cl 8.9-23.9, $\left.P^{2}=89.8 \%\right)$ and $7.7 \%\left(95 \% \mathrm{Cl} 4.2-11.2, P^{2}=62.0 \%\right)$, respectively.
\end{abstract}

Conclusions: This systematic review suggested that about half of the patients with COVID-19 still had residual abnormalities on chest CT and PFT at about 3 months. Further studies with longer follow-up term are warranted.

Keywords: Lung sequelae, COVID-19, Pulmonary function test, Computed tomography

\section{Introduction}

Coronavirus disease 2019 (COVID-19) is caused by a novel coronavirus known as severe acute respiratory syndrome coronavirus 2 (SARS-CoV-2) [1], which was identified to be the cause of pneumonia cases originated in Wuhan, a city in the providence of Hubei, China.

\footnotetext{
*Correspondence: kunotoshiki@gmail.com

1 Department of Medicine, Icahn School of Medicine at Mount Sinai,

Mount Sinai Beth Israel, First Avenue, 16th Street, New York City, NY

10003, USA

Full list of author information is available at the end of the article
}

COVID-19 infection rapidly spread to entire world, leading WHO to declare pandemic on March 11, 2020. As of February 24, 2021, WHO reported $111,593,583$ cases and 2,475,020 deaths [2].

Although COVID-19 is known to cause multiple organ damages, pneumonia is the most frequent manifestation of infection ranging from mild asymptomatic cases to critical respiratory failure requiring ventilatory support [3]. Initial symptoms of COVID-19, lung complications, radiological features, and the management have been extensively reported. Importantly, persistent symptoms 
such as fatigue, dyspnea, joint pain, and chest pain in patients discharged from hospital at 60 days after symptom onset were reported [4]. During the worldwide outbreak of severe acute respiratory syndrome (SARS) in 2003, persistent residual lung fibrosis was reported in $62 \%$ of patients in chest computed tomography obtained on average 36.5 days after hospital admission [5] and can be still present in 7 years after symptom presentation [6]. In addition, impairment in diffusion capacity in SARS survivors has been reported in $25.5 \%$ of patients on average 40.5 days after hospital discharge [7, 8]. Another study also showed forced vital capacity $<80 \%$ predicted in $4.1 \%$ of patients and impaired diffusion capacity in $23.7 \%$ of patients at 1 year after disease onset $[9,10]$. Similarly, studies of Middle East respiratory syndrome (MERS) survivors revealed that $33 \%$ of patients had chest radiograph abnormalities at 80 days after discharge [11] and $37 \%$ of patients had impaired diffusion capacity at 1 year after disease onset [12]. These radiological and functional lung sequelae can detrimentally affect survivors' quality of life. Reports of lung sequelae regarding chest CT findings and PFT observed in patients with clinical recovery from COVID-19 has been increasing recently. Herein, we conducted this systematic review to clarify the characteristics of chest CT findings and PFT results in follow-up period after COVID-19.

\section{Method}

\section{Protocol and registration}

A review protocol does not exist for this analysis.

\section{Eligibility criteria}

Included studies met the following criteria: the study design was an observational study that was published in peer-reviewed journals, the study population was patients with laboratory confirmed SARS-Cov-2 infections confirmed by using a quantitative real-time polymerase chain reaction (RT-PCR) who had follow-up evaluation of chest CT findings or PFT after recovery. Discharge criteria were either confirmed with two consecutive negative results of RT-PCR or clinical stability. Articles that do not contain original data of patients (e.g. guideline, editorial and review) or data obtained within 1 month of follow-up period after clinical recovery were excluded since the purpose of this review was to clarify the characteristics of lung sequelae in mid to long term follow-up period of patients with clinical recovery.

\section{Information sources and search}

All observational studies which included patients with COVID-19 diagnosis and follow-up evaluation of chest CT findings or PFT after clinical recovery were identified using a 2-level strategy. Databases including PubMed and EMBASE were searched through January 20th, 2021. Search items included (SARS-CoV-2 or COVID-19 or COVID-19 [MH]) AND [follow-up OR long-term OR (long term)] AND ((Pulmonary function test or Respiratory function test $[\mathrm{MH}])$ OR (computed tomography OR $\mathrm{CT})$ ).

\section{Study selection and data collection process}

Relevant studies were identified through a manual search of secondary sources including references of initially identified articles, reviews, and commentaries. Two independent authors (M.S. and H.K.) reviewed the search results separately to select the studies based on inclusion and exclusion criteria. Disagreements were resolved by consensus.

\section{Data items}

Outcomes included age, sex, comorbidities, initial COVID-19 symptoms, residual COVID-19 symptoms after hospital discharge, follow-up timing, disease severity, the proportion of abnormalities in chest $\mathrm{CT}$, chest $\mathrm{CT}$ findings at follow-up and type of PFT abnormalities.

\section{Risk of bias in individual studies}

Risk of bias in individual studies was reviewed using assessment of risk of bias in prevalence studies [13] (Additional file 1: Figures S2A, S2B).

\section{Summary measures and synthesis of results}

To calculate frequency of residual lung abnormalities in follow up chest $\mathrm{CT}$ and PFT, retrospective and prospective studies focused on COVID-19 patients who had either follow up chest CT or PFT more than 1 month either after symptom onset or after discharge were utilized and the data regarding the proportion of CT abnormalities, their individual findings in chest $\mathrm{CT}$, the frequency of total PFT abnormality, including obstructive lung function, restrictive lung function, and impaired diffusion capacity were combined using one-group metaanalysis in a random-effect model with DerSimonianLaird method for continuous value and Wald method for discrete value with OpenMetaAnalyst version 12.11.14 (available from http://www.cebm.brown.edu/openm eta/). The frequency of comorbidities, initial COVID-19 symptoms, residual COVID-19 symptoms and proportion of severe cases were calculated by summation of events divided by the total number of patients from all studies the information is available. The clinical severity of COVID-19 was defined according to the WHO interim guidance [14] and the guidance from China "Pneumonia diagnosis and treatment program for novel coronavirus infection (trial version 5)" issued by National Health Commission of the People's Republic of China [15] as 
follows; (1) mild disease: mild symptoms and no evidence of pneumonia in imaging, (2) moderate disease: fever, some respiratory infection symptoms and pneumonia on radiographic imaging, (3) severe disease: meet any of the followings, respiratory distress, respiratory rate $>30 / \mathrm{min}$, $\mathrm{SpO}_{2}<93 \%$ at rest, $\mathrm{PaO}_{2} / \mathrm{FiO}_{2}<300 \mathrm{mmHg}$, (4) Critical disease: meet any of the followings, respiratory failure or requiring mechanical ventilation, shock or other organ failures requiring ICU monitoring. Publication bias was assessed by funnel plots with Egger's test using Comprehensive Meta-Analysis version 3 (available from https:// www.meta-analysis.com/index.php?cart=BTEJ5270189) [16].

\section{Results}

\section{Study selection and study characteristics (Fig. 1)}

We identified 712 articles in total that were reviewed based on the title and abstract. 683 articles were excluded as they were regarding irrelevant topics or did not contain original data. Among the 29 articles, 14 articles were excluded because either they did not clearly mention follow-up timing or the follow-up period was within 1 month after discharge or after symptom onset. Among 15 articles include data of baseline characteristics, 13 articles contained follow-up chest $\mathrm{CT}$ data and 10 articles contained follow-up PFT data. Clinical characteristics of extracted data are shown in Table 1. Among the 15 retrospective and prospective cohort studies with total of 3066 patients, 8 studies were from China and 7 studies were from other countries, including Iran, The Netherlands, Belgium, Canada, Norway, Italy, and Switzerland. They all clearly defined their population as COVID-19 patients who had either follow-up CT or pulmonary function tests more than 1 month after symptom onset or after discharge from hospital. The discharge criteria included two consecutive negative SARS-Cov2 nucleic acid tests detected at least $24 \mathrm{~h}$ apart each in 3 studies [17-19]. The decision to discharge was made clinically based on patients' clinical status and per hospital policy in the other 12 studies [20-31]. Among these studies, 13 studies collected data of chest CT [17-25, 27, 29-31] and 10 studies collected data of PFT [17, 18, 20, 22, 24-29] from the patients with COVID-19 discharged during their study period. Risk of bias of each study is shown in Additional file 1: figure S2.

\section{Baseline characteristics of individual studies (Table 1)}

The follow-up timing of chest CT or pulmonary function tests varied from 1 to 6 months after symptom onset. The average approximate follow-up timing after either symptom onset or hospital discharge was 90 days. Mean age was $56.0 \pm 14.3$, and $54.2 \%$ of the cohort was

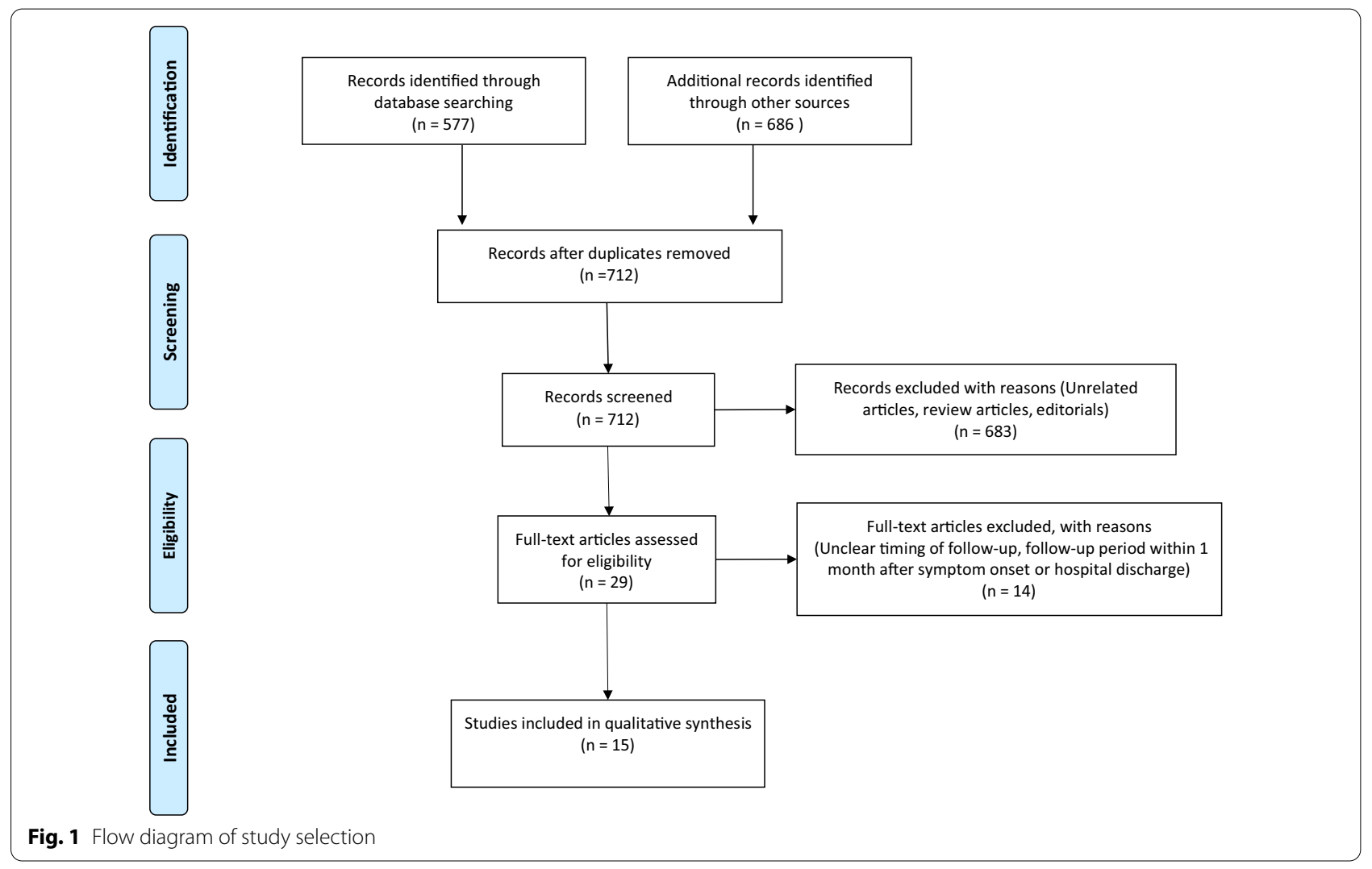




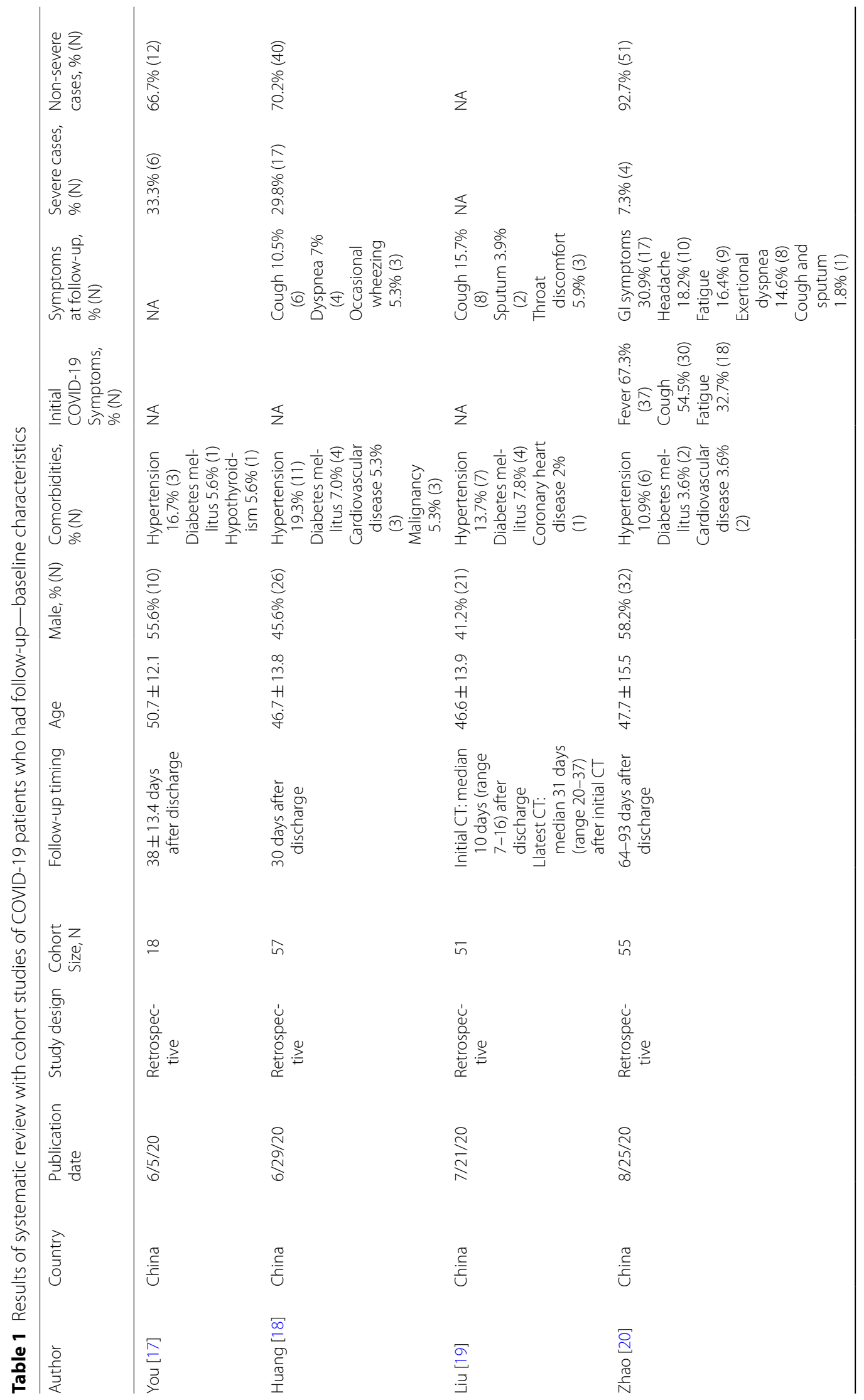




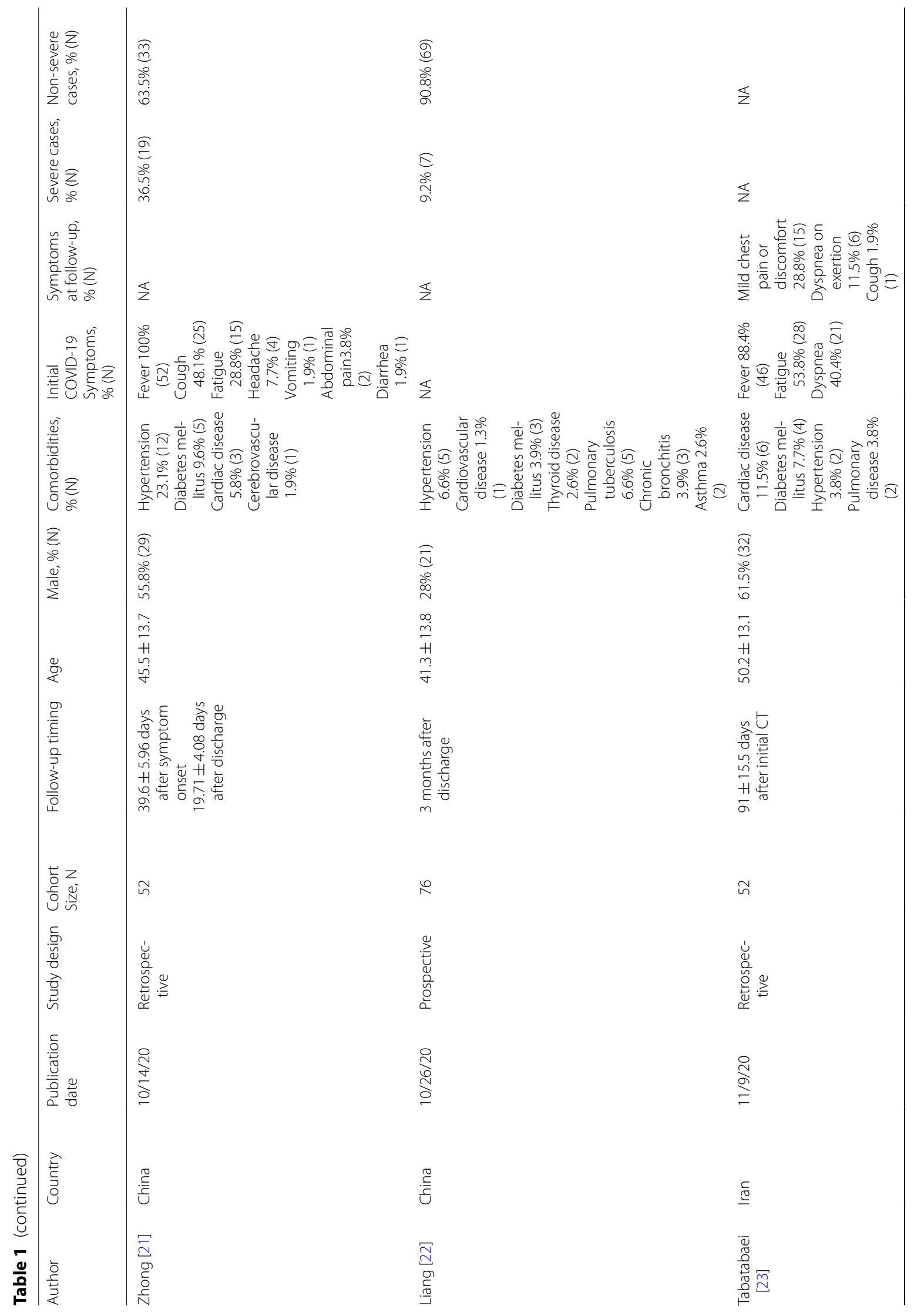


So et al. BMC Pulm Med $\quad$ (2021) 21:97

Page 6 of 16

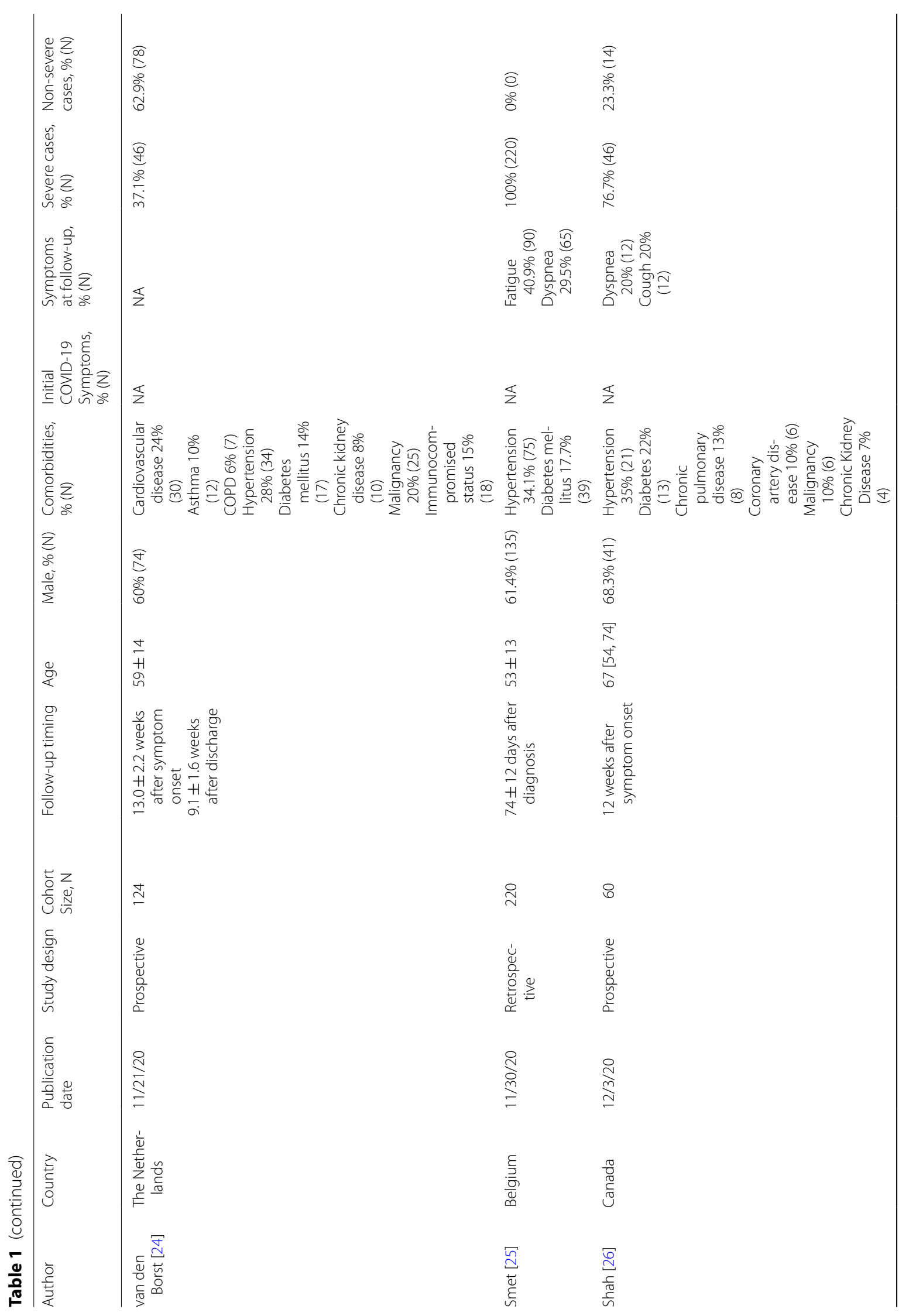




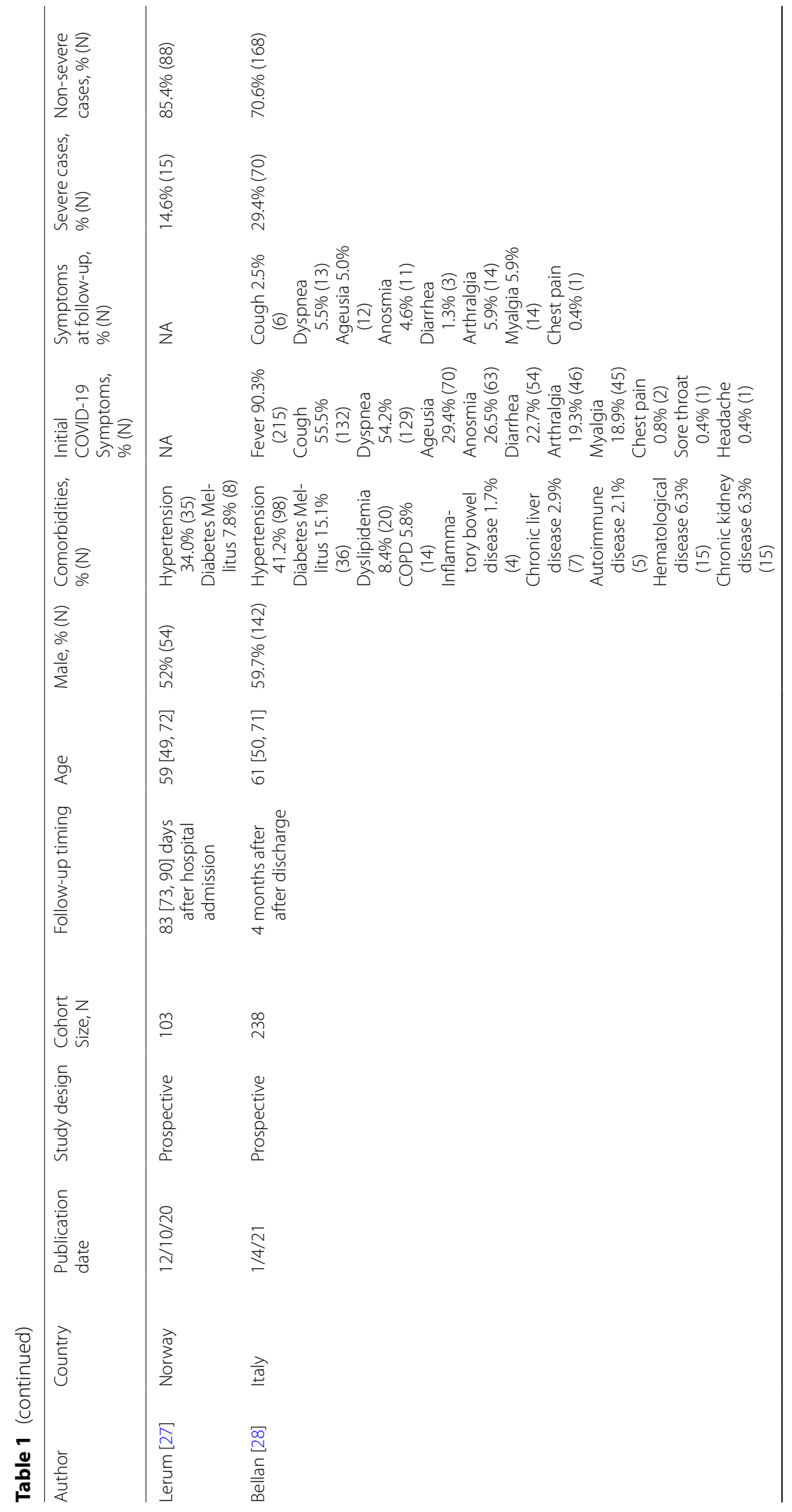




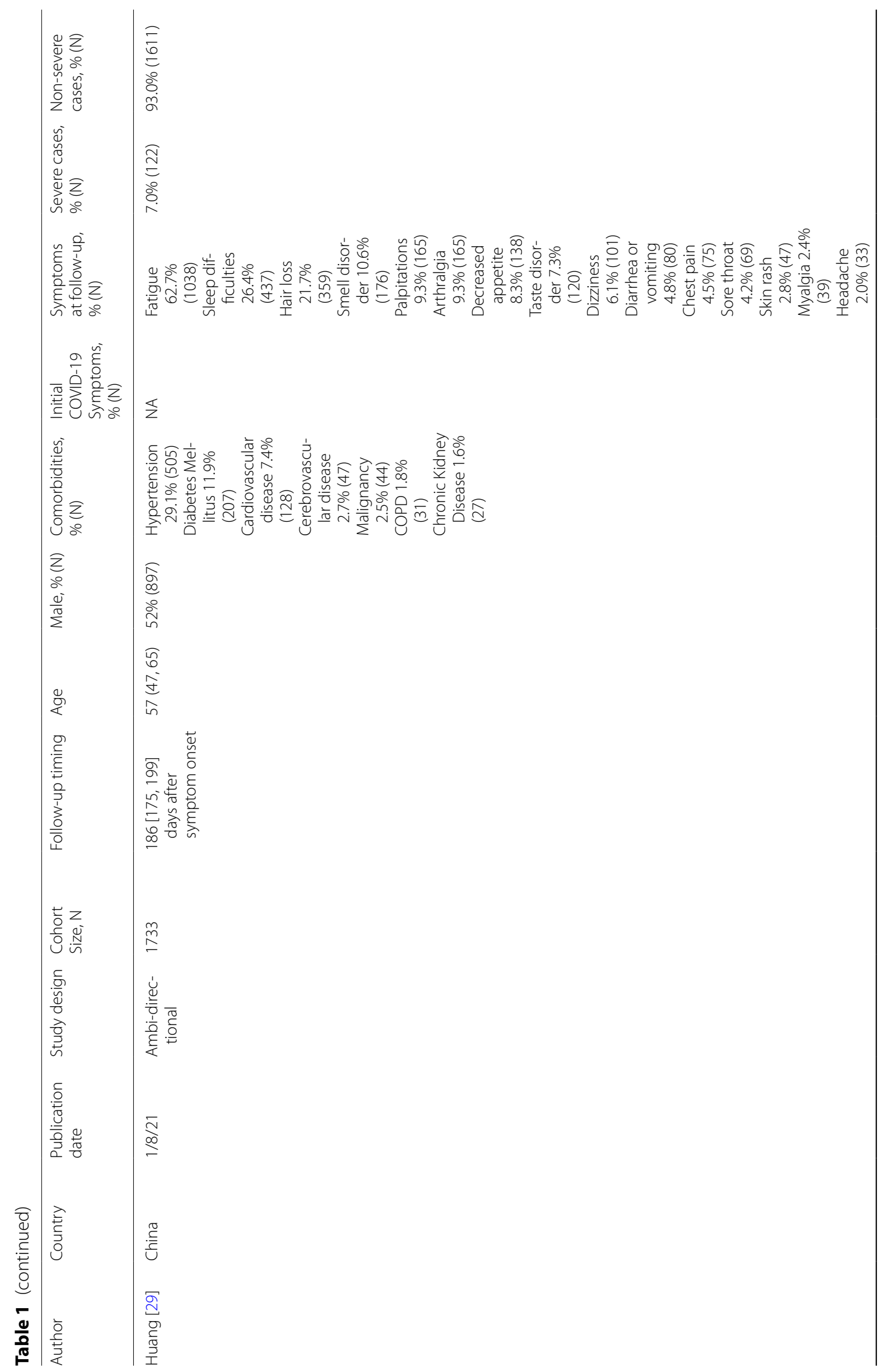




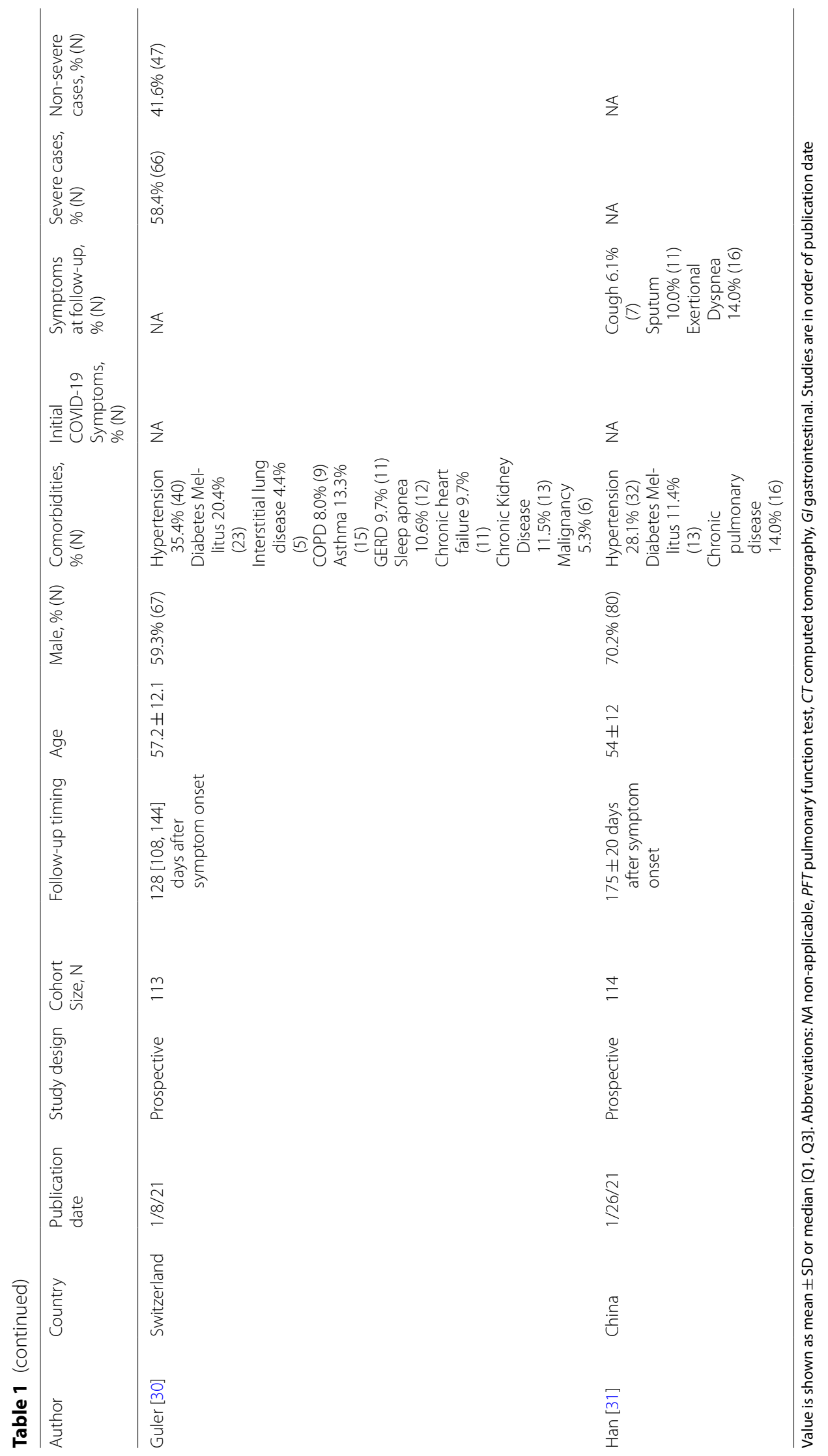


male. Baseline comorbidities were reported in 15 studies: hypertension $28.9 \%$ (886/3066), diabetes mellitus $12.4 \%$ (379/3066), cardiovascular disease 6.2\% (191/3066), chronic pulmonary disease including asthma, chronic obstructive pulmonary disease, chronic bronchitis, pulmonary tuberculosis and interstitial lung disease 3.6\% (110/3066), malignancy $2.7 \%$ (84/3066), chronic kidney disease 2.3\% (69/3066) and cerebrovascular disease 1.6\% (48/3066). Initial COVID-19 symptoms were reported in 4 studies: fever 88.2\% (350/397), cough 47.1\% (187/397), dyspnea $37.8 \%$ (150/397), ageusia $17.6 \%$ (70), anosmia $15.9 \%$ (63/397), fatigue $15.4 \%$ (61/397), diarrhea $13.9 \%$ (55/397), arthralgia $11.6 \%$ (46/397), myalgia $11.3 \%$ (45/397). Residual symptoms at follow-up were reported in 9 studies: fatigue $44.1 \%$ (1137/2580), sleep difficulty $16.9 \%$ (437/2580), hair loss $13.9 \%$ (359/2580), anosmia $7.2 \%(187 / 2,580)$, arthralgia $6.9 \%$ (179/2580), palpitation $6.4 \%(165 / 2580)$, decreased appetite 5.3\% (138/2580), ageusia 5.1\% (132/2580), and dyspnea 4.3\% (112/2580). Severe COVID-19 diseases were observed in $22.4 \%$ $(638 / 2849)$, and mild to moderate cases were observed in $77.6 \%(2211 / 2849)$.

\section{Follow-up CT results after discharge (Table 2)}

13 studies were eligible to assess the residual chest CT findings [17-25, 27, 29-31]. The average approximate follow-up timing after either symptom onset or hospital discharge was 90 days. The frequency of CT abnormalities observed was 55.7\% (95\% confidential interval (CI) 41.2-70.1, $I^{2}=96.2 \%$ ) (Fig. 2). The proportion of each finding observed was as follows; ground glass opacity: $44.1 \%$ (95\% CI 30.5-57.8, $I^{2}=96.2 \%$ ), parenchymal band or fibrous stripe: $33.9 \%$ (95\% CI 18.4-49.4, $I^{2}=95.0 \%$ ), thickening of adjacent pleura: $19.9 \%$ (95\% CI 8.7-31.1, $\left.I^{2}=95.4 \%\right)$, bronchovascular distortion or bronchiectasis: $23.7 \%$ (95\% CI 6.4-40.9, $I^{2}=96.3 \%$ ), interstitial thickening or interlobular septal thickening: $11.1 \%$ (95\% CI 3.7-18.4, $\left.I^{2}=91.6 \%\right)$, consolidation: $8.8 \%$ (95\% CI $3.9-13.8$, $\left.I^{2}=91.0 \%\right)$, pleural effusion: $5.0 \%(95 \% \mathrm{CI}-1.8-11.8$, $I^{2}=78.8 \%$ ) (Additional file 1: Figure S1A-S1G).

\section{Follow-up pulmonary function test after discharge (Table 3)}

We identified 10 studies regarding PFT results in follow up period after 1 month [17, 18, 20, 22, 24-29]. The follow-up timing was approximately 90 days on average. The frequency of follow-up pulmonary function test abnormalities was $44.3 \%$ (95\% CI 32.2-56.4, $I^{2}=82.1 \%$ ) (Fig. 3A). Impaired diffusion capacity was observed in $34.8 \%$ of patients (95\% CI 25.8-43.8, $I^{2}=91.5 \%$ ) (Fig. 3B). Restrictive pattern and obstructive pattern were observed in 16.4\% (95\% CI $8.9-23.9, I^{2}=89.8 \%$ ) (Fig. 3C) and $7.7 \%$ (95\% CI $4.2-11.2, I^{2}=62.0 \%$ ) of patients (Fig. 3D).

\section{Discussion}

The salient findings of our systematic review are the following; (1) the frequency of CT abnormalities after hospital discharge was 55.7\% (95\% CI 41.2-70.1),Ground glass opacity and parenchymal bands/fibrous stripe were the most frequent findings; (2) the frequency of PFT abnormalities after hospital discharge was $44.3 \%$ (95\% CI 32.2-56.4). Despite relatively low frequency of restrictive or obstructive pulmonary dysfunction, impaired diffusion capacity was the most prominent findings among these PFT results. It is noteworthy that the frequency of chest $\mathrm{CT}$ abnormalities was high despite the high proportion of non-severe cases $(77.6 \%, 2211 / 2849$ patients) in this combined data. As previously described in studies from outbreaks of SARS [5], our combined data regarding the frequency of chest CT abnormalities observed in follow-up period of about 3 months in COVID-19 patients was about $60 \%$, and the most frequently observed functional lung sequelae was impaired diffusion capacity. Our combined data of decreased diffusion capacity frequency was higher than that reported in SARS in a similar follow-up period $[7,8]$. Furthermore, compared to radiological lung sequelae of MERS, our data revealed higher rate of residual CT abnormalities [11].

Interestingly, despite the absence of macro level of lung dysfunction represented as reduced lung volume (restrictive lung dysfunction) or impaired airway dynamics (obstructive lung dysfunction), impaired diffusion capacity was more prominent, which indicates the disorder of interstitial structure and microvasculature of lungs. This result may represent underlying microthrombus formation in the lungs as previously reported in autopsy cases of COVID-19 diseases [32-35]. Hypercoagulable state in COVID19 has been reported more and more frequently [36, 37], leading to the robust use of inpatient thromboprophylaxis and extended thromboprophylaxis following hospital discharge for select patients [38]. As demonstrated by Zhao et al. [20], elevated serum D-dimer was associated with decreased diffusion capacity in follow-up PFT. This finding is also consistent with possible microthrombus formation as underlying pathophysiology of COVID-19 disease. Finally, British Thoracic Society guidance on Respiratory follow up of patients with a clinic-radiological diagnosis of COVID-19 pneumonia has defined follow-up algorithms for COVID-19 pneumonia patients, which 


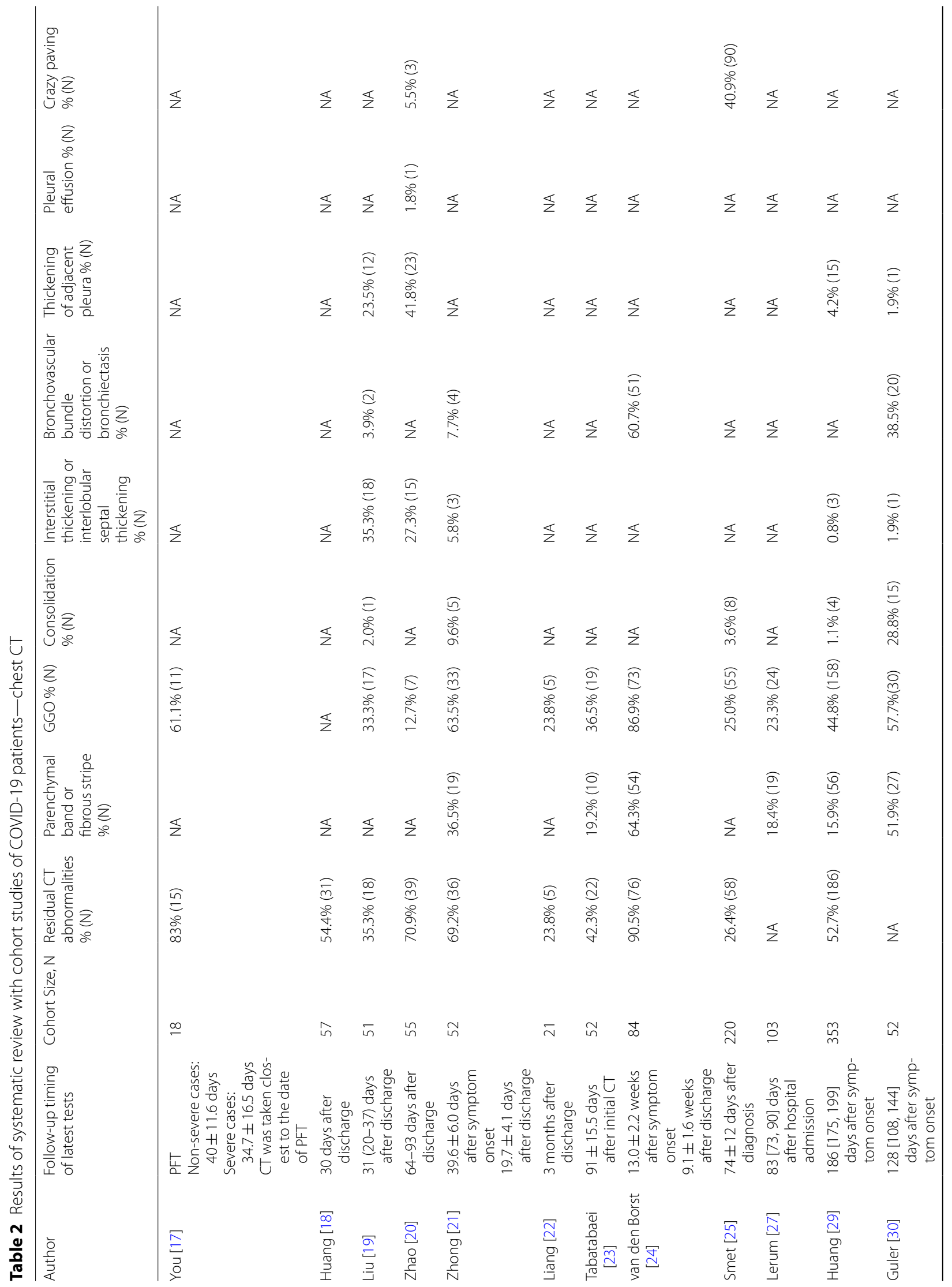




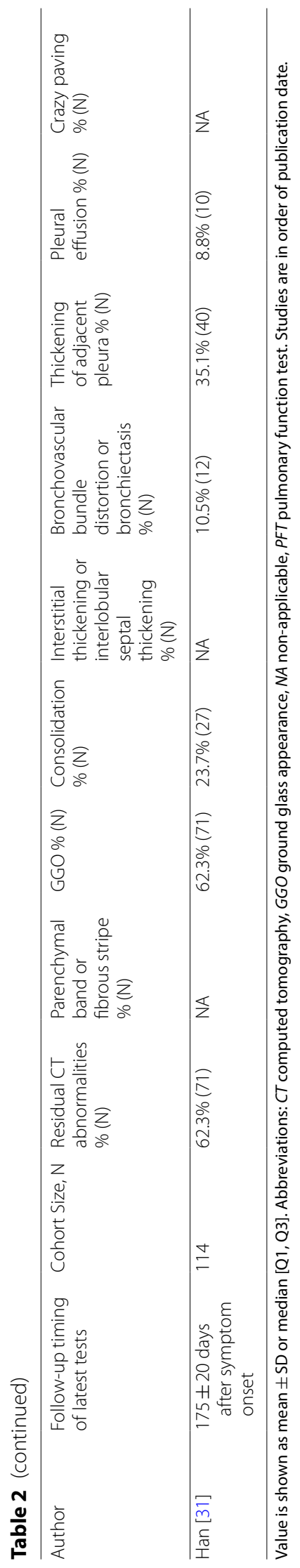




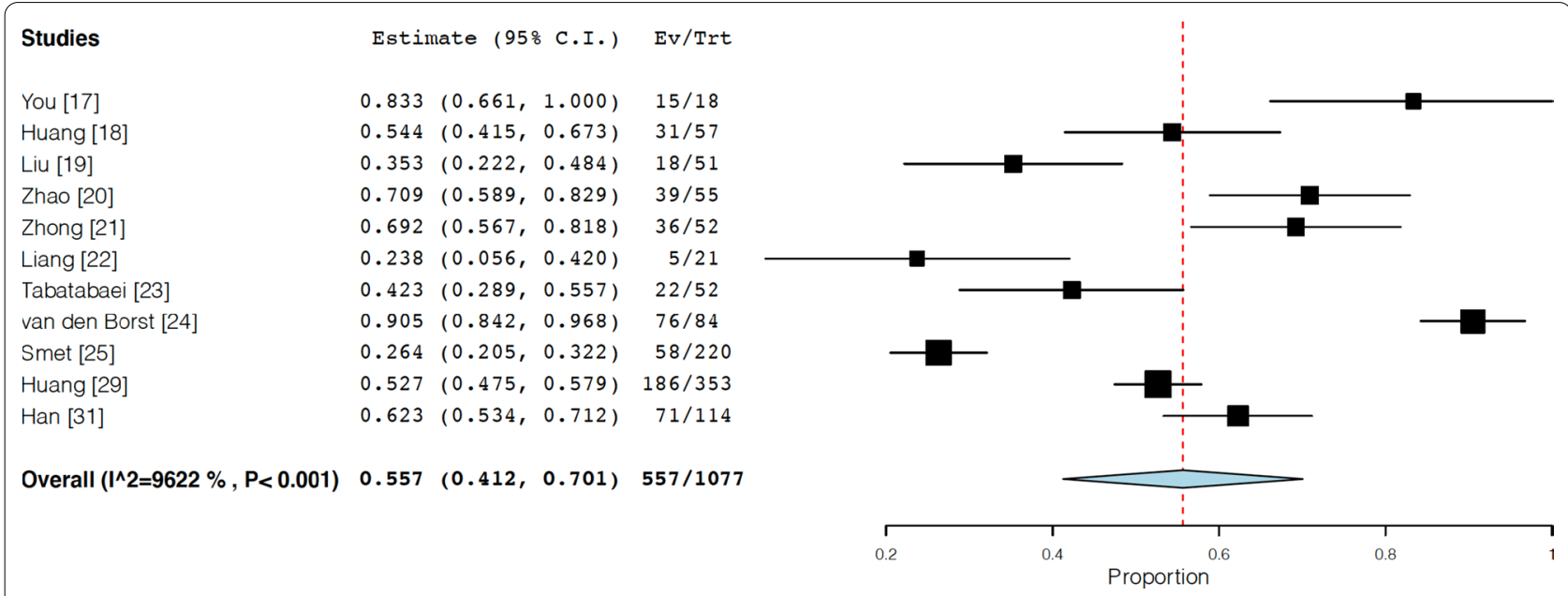

Fig. 2 Forest plots for follow-up chest CT results (random-effects model); frequency of CT abnormalities observed after hospital discharge

suggests to obtain chest radiography follow-up at 12 weeks after discharge and consider full PFT based on severity of COVID-19 disease. Any abnormalities in these tests encourage us to take high resolution CT or CT pulmonary angiography for possible residual interstitial lung disease or pulmonary embolism and recommend referral to either interstitial lung disease or pulmonary hypertension specialist services [39].

This study has several limitations. First, the description of follow up timing was variable and inconsistent

Table 3 Results of systematic review with cohort studies of COVID-19 patients—pulmonary function test

\begin{tabular}{|c|c|c|c|c|c|c|}
\hline Author & Follow-up timing after discharge & Cohort Size, N & $\begin{array}{l}\text { PFT abnormalities } \\
\text { at follow-up, \% (N) }\end{array}$ & $\begin{array}{l}\text { Restrictive pattern } \\
\%(\mathrm{~N}) \\
\text { VCmax } \% \\
\text { predicted }<80 \% \text { or } \\
\text { VCmax }<\text { LLN } \\
\text { OR } \\
\text { FVC } \% \text { predicted }<80 \% \\
\text { or FVC }<\text { LLN } \\
\text { OR } \\
\text { TLC z-score }<-1.64 \text { or } \\
\text { TLC } \% \text { predicted }<80 \%\end{array}$ & $\begin{array}{l}\text { Obstructive } \\
\text { pattern \% } \\
\text { (N) } \\
\text { FEV1/ } \\
\text { FVC }<70 \% \\
\text { OR } \\
\text { FEV1/ } \\
\text { VCmax }<\text { LLN } \\
\%\end{array}$ & $\begin{array}{l}\text { Diffusion } \\
\text { Impairment } \\
\%(N) \\
\text { DLCO }<80 \% \\
\text { predicted } \\
\text { OR } \\
\text { DLCO }<\text { LLN }\end{array}$ \\
\hline You [17] & $38 \pm 13.4$ days after discharge & 18 & $38.9 \%(7)$ & $16.7 \%(3)$ & $16.7 \%(3)$ & NA \\
\hline Huang [18] & 30 days after discharge & 57 & NA & $10.5 \%(6)$ & $1.8 \%(1)$ & $52.6 \%(30)$ \\
\hline Zhao [20] & 64-93 days after discharge & 55 & $25.5 \%(14)$ & $10.9 \%(6)$ & $9.1 \%(5)$ & $16.4 \%(9)$ \\
\hline Liang [22] & 3 months after discharge & 76 & $42.1 \%(32)$ & NA & $6.6 \%(5)$ & $19.7 \%(15)$ \\
\hline van den Borst [24] & $\begin{array}{l}13.0 \pm 2.2 \text { weeks after symptom onset } \\
9.1 \pm 1.6 \text { weeks after discharge }\end{array}$ & 84 & NA & $9.5 \%(8)$ & $15.5 \%(13)$ & $48.8 \%(41)$ \\
\hline Smet [25] & $74 \pm 12$ days after diagnosis & 220 & $54.1 \%(119)$ & $38.2 \%(84)$ & NA & $21.8 \%(48)$ \\
\hline Shah [26] & 12 weeks after symptom onset & 60 & $58.3 \%(35)$ & $23.3 \%(14)$ & $11.7 \%(7)$ & $51.7 \%(31)$ \\
\hline Lerum [27] & $\begin{array}{l}83[73,90] \text { days after hospital admis- } \\
\text { sion }\end{array}$ & 1032 & NA & $6.8 \%(7)$ & NA & $23.3 \%(24)$ \\
\hline Bellan [28] & 4 months after after discharge & 224 & NA & NA & NA & $50.4 \%(113)$ \\
\hline Huang [29] & $\begin{array}{l}186[175,199] \text { days after symptom } \\
\text { onset }\end{array}$ & 349 & NA & $16.0 \%(56)$ & $6.3 \%(22)$ & $32.7 \%(114)$ \\
\hline
\end{tabular}

Value is shown as mean \pm SD or median [Q1, Q3]. Abbreviations: PFT pulmonary function test, LLN lower limit of normal, VC vital capacity, FVC forced vital capacity, TLC total lung capacity, FEV1 forced expiratory volume in $1 \mathrm{~s}, D_{L C O}$ diffusion capacity of the lungs for carbon, NA non-applicable. Studies are in order of publication date 


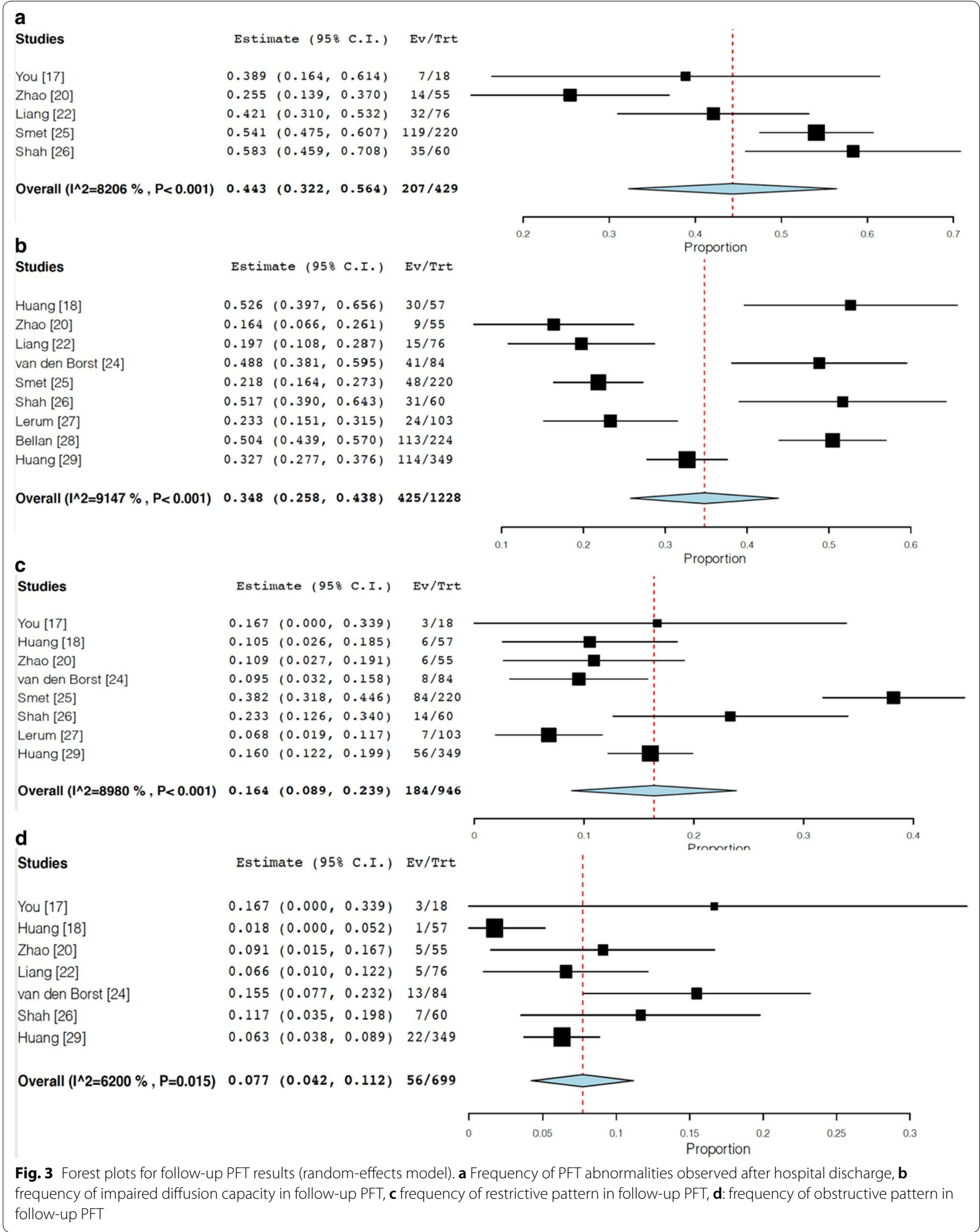


between studies such as different starting point of duration and scale of duration, which made it difficult to precisely compare the proportion of patients with residual abnormalities. Second, each article reported CT abnormalities findings with different radiological terminology and PFT abnormalities were reported with different definition of restrictive or obstructive pattern, which made it difficult to accurately assess the proportion of each finding. Third, some studies reported only moderate severity of COVID-19 cases while others included moderate to critical diseases, which can be a factor leads to selection bias as well as low participation of patients in some studies which leads to non-response bias (Additional file 1: Figure S2A-S2B). More follow up data need to be published in the near future and further depict the long-term characteristics of radiological findings and lung function in COVID-19 disease.

\section{Conclusion}

This systematic review assessed the post discharge chest CT and pulmonary function tests in COVID19 patients in follow-up period of about 3 months. The frequency of residual chest $\mathrm{CT}$ abnormalities observed was $55.7 \%$, and ground glass opacity and parenchymal band were most frequent. Follow-up pulmonary function test was abnormal in $44.3 \%$, mainly presenting decreased diffusion capacity. Further studies with longer term follow-up data are warranted to clarify how long these abnormalities are persistent, which will be helpful to manage patients with longterm sequelae from COVID-19 disease.

\section{Supplementary Information}

The online version contains supplementary material available at https://doi. org/10.1186/s12890-021-01463-0.

\begin{abstract}
Additional file 1: Supplemental Figure S1. Forrest plots of the proportion of (A) ground glass opacity in follow-up chest CT; (B) parenchymal band or fibrous stripe in follow-up chest $\mathrm{CT}$; $(\mathrm{C})$ adjacent pleural thickening in follow-up chest CT; (D) bronchovascular distortion or bronchiectasis in follow-up chest CT; (E) interstitial thickening or interlobular septal thickening in follow-up chest $C T$; (F) consolidation in follow-up chest $C T$; $(G)$ pleural effusion in follow-up chest CT. Supplemental Figure S2. Risk of bias (A): Risk of bias graph: review authors'judgements about each risk of bias item presented as percentages across all included studies (B): Risk of bias summary: review authors'judgements about each risk of bias item for each included study. +, low risk of bias; -, high risk of bias. Supplemental Figure S3. Publication bias Funnel plots of precision by point estimate of (A) chest CT abnormalities at follow-up; (B) PFT abnormalities at follow-up; (C) impaired DLCO at follow-up; (D) restrictive pattern in follow-up PFT; (E) obstructive pattern in follow-up PFT.
\end{abstract}

\section{Acknowledgements}

We would like to thank the Keio Donner Project Team.

\section{Authors' contributions}

All authors had full access to all the data in the study and takes responsibility for the integrity of the data and accuracy of the data analysis. Study concept and design: MS, HK, TK. Data Curation: MS, TK. Acquisition, analysis, or interpretation of data: All authors. Drafting of the manuscript: MS, HK, TK. Critical revision of the manuscript for important intellectual content: All authors. Statistical analysis: MS, HT, TK. Administrative, technical, or material support: KF, HT. Study supervision: HK, KF, HT, TK. All authors read and approved the final manuscript.

\section{Funding}

This research was supported by MHLW Program Grant Number JPMH20CA2054 and the Keio Donner Project.

\section{Availability of data and materials}

We used the data from published data given its nature of systematic review and meta-analysis.

\section{Declarations}

Ethics approval and consent to participate

Not applicable given using data of published data for systematic review and meta-analysis.

\section{Consent for publication}

Not applicable given using data of published data for systematic review and meta-analysis.

\section{Competing interests}

$\mathrm{KF}$ received honoraria from Boehringer Ingelheim and AstraZeneca. Others authors have no disclosure.

\section{Author details \\ ${ }^{1}$ Department of Medicine, Icahn School of Medicine at Mount Sinai, Mount Sinai Beth Israel, First Avenue, 16th Street, New York City, NY 10003, USA. ${ }^{2}$ Divi- sion of Pulmonary Medicine, Department of Medicine, Keio University School of Medicine, Tokyo, Japan. ${ }^{3}$ Division of Cardiovascular Surgery, Shizuoka Medi- cal Center, Shizuoka, Japan.}

Received: 14 November 2020 Accepted: 9 March 2021

Published online: 22 March 2021

References

1. Lu R, Zhao X, Li J, et al. Genomic characterisation and epidemiology of 2019 novel coronavirus: implications for virus origins and receptor binding. Lancet. 2020;395(10224):565-74.

2. World Health Organization. COVID-19 dashboard. https://covid19.who. int/.

3. Richardson S, Hirsch JS, Narasimhan M, et al. Presenting characteristics, comorbidities, and outcomes among 5700 patients hospitalized with COVID-19 in the New York City area. JAMA. 2020;323(20):2052.

4. Carfi A, Bernabei R, Landi F. Gemelli against COVID-19 post-acute care study group. Persistent symptoms in patients after acute COVID-19. JAMA. 2020;324(6):603-5.

5. Antonio GE, Wong KT, Hui DS, et al. Thin-section CT in patients with severe acute respiratory syndrome following hospital discharge: preliminary experience. Radiology. 2003;228(3):810-5.

6. Wu X, Dong D, Ma D. Thin-section computed tomography manifestations during convalescence and long-term follow-up of patients with severe acute respiratory syndrome (SARS). Med Sci Monit. 2016;22:2793-9.

7. Xie L, Liu Y, Fan B, et al. Dynamic changes of serum SARS-coronavirus IgG, pulmonary function and radiography in patients recovering from SARS after hospital discharge. Respir Res. 2005;6:5.

8. Xie L, Liu Y, Xiao Y, et al. Follow-up study on pulmonary function and lung radiographic changes in rehabilitating severe acute respiratory syndrome patients after discharge. Chest. 2005;127:2119-24. 
9. Hui DS, Joynt GM, Wong KT, et al. Impact of severe acute respiratory syndrome (SARS), on pulmonary function, functional capacity and quality of life in a cohort of survivors. Thorax. 2005;60:401-9.

10. Hui DS, Wong KT, Ko FW, et al. The 1-year impact of severe acute respiratory syndrome on pulmonary function, exercise capacity, and quality of life in a cohort of survivors. Chest. 2005;128:2247-61.

11. Das KM, Lee EY, Singh R, et al. Follow-up chest radiographic findings in patients with MERSCOV after recovery. Indian J Radiol Imaging. 2017;27(3):342-9.

12. Park WB, Jun KI, Kim G, et al. Correlation between pneumonia severity and pulmonary complications in middle east respiratory syndrome. J Korean Med Sci. 2018;33:e169.

13. Hoy D, Brooks $P$, Woolf $A$, et al. Assessing risk of bias in prevalence studies: modification of an existing tool and evidence of interrater agreement. J Clin Epidemiol. 2012;65:934-9.

14. World Health Organization. Clinical management of severe acute respiratory infection when COVID-19 is suspected. https://www.who. int/publications/i/item/clinical-management-of-covid-19. Date last updated: 27 May 2020.

15. National Health Commission \& State Administration of Traditional Chinese Medicine. Diagnosis and Treatment Protocol for Novel Coronavirus Pneumonia (Trial Version 7). www.who.int/docs/default-source/ wpro---documents/countries/china/covid-19-briefing-nhc/1-clinicalprotocols-for-the-diagnosis-and-treatment-of-covid-19-v7.pdf?sfvrsn= c6cbfba4_2. Date last updated: 3 March 2020

16. Egger M, Davey Smith G, Schneider M, Minder C. Bias in meta-analysis detected by a simple, graphical test. BMJ. 1997;315(7109):629-34

17. You J, Zhang L, Ni-Jia-Ti MY, Zhang J, Hu F, Chen L, Dong Y, Yang K, Zhang B, Zhang $S$. Anormal pulmonary function and residual CT abnormalities in rehabilitating COVID-19 patients after discharge. J Infect. 2020;81(2):e150-2.

18. Huang Y, Tan C, Wu J, Chen M, Wang Z, Luo L, Zhou X, Liu X, Huang X, Yuan S, Chen C, Gao F, Huang J, Shan H, Liu J. Impact of coronavirus disease 2019 on pulmonary function in early convalescence phase. Respir Res. 2020;21(1):163.

19. Liu D, Zhang W, Pan F, Li L, Yang L, Zheng D, Wang J, Liang B. The pulmonary sequalae in discharged patients with COVID-19: a short-term observational study. Respir Res. 2020;21(1):125.

20. Zhao YM, Shang YM, Song WB, Li QQ, Xie H, Xu QF, Jia JL, Li LM, Mao HL, Zhou XM, Luo H, Gao YF, Xu AG. Follow-up study of the pulmonary function and related physiological characteristics of COVID-19 survivors three months after recovery. EClinicalMedicine. 2020;25:100463.

21. Zhong L, Zhang S, Wang J, Zhao X, Wang K, Ding W, Xing Z, Shen J. Analysis of chest CT results of coronavirus disease 2019 (COVID-19) patients at first follow-up. Can Respir J. 2020;1 (2020):5328267.

22. Liang L, Yang B, Jiang N, Fu W, He X, Zhou Y, Ma WL, Wang X. Three-month follow-up study of survivors of coronavirus disease 2019 after discharge. J Korean Med Sci. 2020;35(47):e418.

23. Tabatabaei SMH, Rajebi H, Moghaddas F, Ghasemiadl M, Talari H. Chest CT in COVID-19 pneumonia: what are the findings in mid-term follow-up? Emerg Radiol. 2020;27(6):711-9.

24. van den Borst B, Peters JB, Brink M, Schoon Y, Bleeker-Rovers CP, Schers $H$, van Hees HWH, van Helvoort $H$, van den Boogaard $M$, van der Hoeven H, Reijers MH, Prokop M, Vercoulen J, van den Heuvel M. Comprehensive health assessment three months after recovery from acute COVID-19. Clin Infect Dis. 2020; ciaa1750.

25. Smet J, Stylemans D, Hanon S, Ilsen B, Verbanck S, Vanderhelst E. Clinical status and lung function 10 weeks after severe SARS-CoV-2 infection. Respir Med. 2021;176:106276.

26. Shah AS, Wong AW, Hague CJ, Murphy DT, Johnston JC, Ryerson CJ, Carlsten C. A prospective study of 12 -week respiratory outcomes in COVID-19-related hospitalisations. Thorax. 2020; thoraxjnl-2020-216308.

27. Lerum TV, Aaløkken TM, Brønstad E, Aarli B, Ikdahl E, Lund KMA, Durheim MT, Rodriguez JR, Meltzer C, Tonby K, Stavem K, Skjønsberg OH, Ashraf $H$, Einvik G. Dyspnoea, lung function and CT findings three months after hospital admission for COVID-19. Eur Respir J. 2020;10:2003448.

28. Bellan M, Soddu D, Balbo PE, Baricich A, Zeppegno P, Avanzi GC, Baldon G, Bartolomei G, Battaglia M, Battistini S, Binda V, Borg M, Cantaluppi V
Castello LM, Clivati E, Cisari C, Costanzo M, Croce A, Cuneo D, De Benedittis C, De Vecchi S, Feggi A, Gai M, Gambaro E, Gattoni E, Gramaglia C, Grisafi L, Guerriero C, Hayden E, Jona A, Invernizzi M, Lorenzini L, Loreti L, Martelli M, Marzullo P, Matino E, Panero A, Parachini E, Patrucco F, Patti G, Pirovano A, Prosperini P, Quaglino R, Rigamonti C, Sainaghi PP, Vecchi C, Zecca E, Pirisi M. Respiratory and psychophysical sequelae among patients with COVID-19 four months after hospital discharge. JAMA Netw Open. 2021;4(1):e2036142.

29. Huang C, Huang L, Wang Y, Li X, Ren L, Gu X, Kang L, Guo L, Liu M, Zhou X, Luo J, Huang Z, Tu S, Zhao Y, Chen L, X X D, Li Y, Li C, Peng L, Li Y, Xie W, Cui D, Shang L, Fan G, Xu J, Wang G, Wang Y, Zhong J, Wang C, Wang J, Zhang D, Cao B. 6-month consequences of COVID-19 in patients discharged from hospital: a cohort study. Lancet. 2021;397(10270):220-32.

30. Guler SA, Ebner L, Beigelman C, Bridevaux PO, Brutsche M, Clarenbach C, Garzoni C, Geiser TK, Lenoir A, Mancinetti M, Naccini B, Ott SR, Piquilloud L, Prella M, Que YA, Soccal PM, von Garnier C, Funke-Chambour M. Pulmonary function and radiological features four months after COVID-19: first results from the national prospective observational Swiss COVID-19 lung study. Eur Respir J. 2021;8:2003690.

31. Han X, Fan Y, Alwalid O, Li N, Jia X, Yuan M, Li Y, Cao Y, Gu J, Wu H, Shi H. Six-month follow-up chest CT findings after severe COVID-19 pneumonia. Radiology. 2021;26:203153.

32. Magro C, Mulvey JJ, Berlin D, Nuovo G, Salvatore S, Harp J, Baxter-Stoltzfus A, Laurence J. Complement associated microvascular injury and thrombosis in the pathogenesis of severe COVID-19 infection: A report of five cases. Transl Res. 2020;220:1.

33. Connors JM, Levy JH. Thromboinflammation and the hypercoagulability of COVID-19. J Thromb Haemost. 2020;18(7):1559.

34. Menter T, Haslbauer JD, Nienhold R, Savic S, Hopfer H, Deigendesch N, Frank S, Turek D, Willi N, Pargger H, Bassetti S, Leuppi JD, Cathomas G, Tolnay M, Mertz KD, Tzankov A. Postmortem examination of COVID-19 patients reveals diffuse alveolar damage with severe capillary congestion and variegated findings in lungs and other organs suggesting vascular dysfunction. Histopathology. 2020;77(2):198-209.

35. Ackermann M, Verleden SE, Kuehnel M, Haverich A, Welte T, Laenger F, Vanstapel A, Werlein C, Stark H, Tzankov A, Li WW, Li VW, Mentzer SJ, Jonigk D. Pulmonary vascular endothelialitis, thrombosis, and angiogenesis in Covid-19. N Engl J Med. 2020;383(2):120.

36. Klok FA, Kruip MJHA, van der Meer NJM, Arbous MS, Gommers DAMPJ, Kant KM, Kaptein FHJ, van Paassen J, Stals MAM, Huisman MV, Endeman $\mathrm{H}$. Incidence of thrombotic complications in critically ill ICU patients with COVID-19. Thromb Res. 2020;191:145-7.

37. Bilaloglu S, Aphinyanaphongs Y, Jones S, Iturrate E, Hochman J, Berger JS. Thrombosis in hospitalized patients with COVID-19 in a New York City health system. JAMA. 2020;324(8):799-801.

38. Bikdeli B, Madhavan MV, Jimenez D, Chuich T, Dreyfus I, Driggin E, Nigoghossian C, Ageno W, Madjid M, Guo Y, Tang LV, Hu Y, Giri J, Cushman M, Quéré I, Dimakakos EP, Gibson CM, Lippi G, Favaloro EJ, Fareed J, Caprini JA, Tafur AJ, Burton JR, Francese DP, Wang EY, Falanga A, McLintock C, Hunt BJ, Spyropoulos AC, Barnes GD, Eikelboom JW, Weinberg I, Schulman S, Carrier M, Piazza G, Beckman JA, Steg PG, Stone GW, Rosenkranz S, Goldhaber SZ, Parikh SA, Monreal M, Krumholz HM, Konstantinides SV, Weitz JI, Lip GYH. Global COVID-19 Thrombosis Collaborative Group, Endorsed by the ISTH, NATF, ESVM, and the IUA, Supported by the ESC Working Group on Pulmonary Circulation and Right Ventricular Function. COVID-19 and thrombotic or thromboembolic disease: implications for prevention, antithrombotic therapy, and follow-up: JACC state-of-the-art review. J Am Coll Cardiol. 2020;75(23):2950-2973.

39. George PM, Barratt SL, Condliffe R, Desai SR, Devaraj A, Forrest I, Gibbons MA, Hart N, Jenkins RG, McAuley DF, Patel BV, Thwaite E, Spencer LG. Respiratory follow-up of patients with COVID-19 pneumonia. Thorax. 2020: thoraxjnl-2020-215314.

\section{Publisher's Note}

Springer Nature remains neutral with regard to jurisdictional claims in published maps and institutional affiliations. 